\title{
POLYMORPHISM IN AN ISLAND POPULATION OF THE CALIFORNIA VOLE, MICROTUS CALIFORNICUS
}

\author{
REPRODUCTIVE FITNESS OF GENOTYPES IN DIFFERING \\ CONTROLLED ENVIRONMENTS
}

\author{
AYESHA E. GILL* \\ Museum of Vertebrate Zoology and Department of Genetics, \\ University of California, Berkeley 94720
}

Received 30.xii.75

\begin{abstract}
SUMmary
The effects of two seasonally varying factors on the breeding success of different genotypes were assessed in separate controlled experiments in the laboratory. Homozygous and heterozygous agouti morphs and a homozygous buffy morph bred from a polymorphic island population of the California vole were the subjects of the study. Significant genotypic differences were found in the reproductive output of an experimental group in a cold $\left(6^{\circ} \mathrm{C}\right)$ environment compared to a control sibling group at ambient fluctuating temperatures. In a second experiment, reproductive output was significantly higher for agouti, but not buffy morphs, given a green food supplement, compared to their sibs on a dry food diet. Genotypic differences in growth patterns of the offspring were also found. Temperature and availability of green vegetation vary seasonally in central coastal California. The genotypically different responses to these factors is discussed in relation to a seasonal fluctuation in the proportions of the coat colour morphs found on Brooks Island.
\end{abstract}

\section{Introduction}

An island population of the California vole, Microtus californicus, is polymorphic for coat colour. As part of a study on the mechanisms maintaining this polymorphism, I compared reproductive fitnesses of the genotypes in differing controlled environments.

Voles were discovered on Brooks Island (San Francisco Bay) in 1959, shortly after they invaded (Lidicker and Anderson, 1962), and their population dynamics were followed for the next 13 years (Lidicker, 1973). Lidicker (1963) demonstrated that a new coat colour morph, buffy, found on the island is homozygous recessive $(b f / b f)$. The agouti phenotype is controlled by a dominant allele $(+)$, the heterozygote being morphologically indistinguishable from the homozygote. Although the $b f$ allele has been found in two other populations (Gill, 1972), the buffy phenotype has not been observed in mainland populations.

According to laboratory breeding results (Gill, 1972, 1976b), the heterozygotes are reproductively superior, which could lead to stable polymorphism. On Brooks Island, however, there are also seasonal changes in the frequencies of the morphs (Lidicker, 1966, 1973 and unpublished; summarised in Gill, 1976b). Differential genotypic responses to seasonal variables may be involved in these regular fluctuations of genotypic

* Present address: Department of Biology, University of California, Los Angeles. $38 / 1-\mathrm{A}$ 
frequencies. Two important seasonal variables are temperature and the availability of green plants, which flourish with the winter rains and wither during the summers in this Mediterranean climate. To assess genotypic responses to these variables I conducted two laboratory experiments-one on the effect of low, compared to ambient fluctuating, temperatures on the reproductive success of the three genotypes and another on the importance of green vegetation to the animals' reproduction.

\section{Materials And methods}

The laboratory colony derived from Brooks Island voles consisted of the following types: A, agouti homozygote $(+/+)$; B, buffy homozygote $(b f / b f)$; and $\mathrm{H}$, agouti heterozygote $(+/ b f)$. Some of the agouti homozygotes had heritable white chin spots (Gill, 1976a), denoted by a superscript "w". Breeding pairs were kept in separate metal cages provided with wood shavings and cotton and supplied with dry laboratory pellets (Purina \# 56), water ad libitum, and 50-70 g lettuce twice a week.

The low temperature experimental group, kept in a refrigerated room at an approximatcly constant $6^{\circ} \mathrm{C}$ temperature, consisted of mated pairs of the types $\mathrm{A} \times \mathrm{A}, \mathrm{A}^{\mathrm{w}} \times \mathrm{A}^{\mathrm{w}}, \mathrm{B} \times \mathrm{B}$, and $\mathrm{H} \times \mathrm{H}$. The control group, in which each pair consisted of siblings of the corresponding pair in the experimental group, were housed in a non-refrigerated room which underwent daily fluctuations in temperature and humidity. These daily temperature fluctuations ranged from a high of $18^{\circ}-27^{\circ}$ in October to a low of $9^{\circ}-23^{\circ}$ in February, rising again to $15^{\circ}-18^{\circ}$ in May. The rooms were illuminated from 7 a.m. to 7 p.m. by artificial light only. Twenty pairs of experimental animals were kept continuously in the cold room from 26th October 1970 until 12th March 1971, when thcy were replaced by a second group which remained until 25th May 1971. Their matched control groups were maintained for the same periods.

The experiment on the effect of green food in the diet on reproduction was conducted from 1st May to 20th July 1971. Twenty-one pairs of the three genotypes $\mathrm{A} \times \mathrm{A}, \mathrm{B} \times \mathrm{B}$, and $\mathrm{H} \times \mathrm{H}$ comprised the "green" group, receiving $80 \mathrm{~g}$ of lettuce per pair twice weekly in addition to dry food and water. Their matched siblings in the control "dry" group received only dry food and water, no lettuce. Both groups were kept at ambient temperatures.

Reproductive data and weights of litters were recorded. The young were weighed twice weekly until removed from their parents at 16 to 18 days after birth.

\section{Results}

\section{(i) Experiment on effect of cold}

Important genotypic differences in fertility and juvenile mortality emerged in this study (table 1). The homozygous recessive buffy genotypes are less fertile at ambient temperatures than homozygous agoutis or heterozygotes $\left(\mathrm{P}=0.05 ; \chi^{2}\right.$-test of number of fertile compared to non-fertile crosses). Fertility of buffy crosses bred at ambient temperatures was found to be low ( 52 per cent of 23 crosses) in an earlier laboratory study also (Gill, 1976b). The present study, however, shows that buffy fertility 
TABLE 1

Reproductive data from cold temperature experiments

\begin{tabular}{|c|c|c|c|c|c|c|c|}
\hline $\begin{array}{c}\text { Parental } \\
\text { type } \\
+\times ð\end{array}$ & & $\begin{array}{l}\text { No. of } \\
\text { crosses }\end{array}$ & $\begin{array}{c}\% \text { fertile } \\
\text { crosses }\end{array}$ & $\begin{array}{l}\text { No. of } \\
\text { litters }\end{array}$ & $\begin{array}{l}\text { No. } \\
\text { born }\end{array}$ & $\begin{array}{c}\% \\
\text { weaned }\end{array}$ & $\begin{array}{r}\text { Mean } \\
\text { litter } \\
\text { size }\end{array}$ \\
\hline \multirow[t]{2}{*}{$\mathrm{A} \times \mathrm{A}$} & Cold & 8 & $87 \cdot 5$ & 20 & 96 & $62 \cdot 5$ & $4 \cdot 8$ \\
\hline & Control & 8 & $87 \cdot 5$ & 23 & 103 & $89 \cdot 3$ & $4 \cdot 5$ \\
\hline \multirow[t]{2}{*}{$A^{w} \times A^{w}$} & Cold & 6 & $100 \cdot 0$ & 16 & 70 & $68 \cdot 6$ & $4 \cdot 4$ \\
\hline & Control & 6 & $83 \cdot 3$ & 17 & 71 & $96 \cdot 8$ & $4 \cdot 2$ \\
\hline \multirow[t]{2}{*}{$\mathrm{B} \times \mathrm{B}$} & Cold & 11 & $81 \cdot 8$ & 26 & 133 & $51 \cdot 1$ & $5 \cdot 1$ \\
\hline & Control & 11 & $36 \cdot 4$ & 11 & 60 & $100 \cdot 0$ & $5 \cdot 5$ \\
\hline \multirow[t]{2}{*}{$\mathrm{H} \times \mathbf{H}$} & Cold & 12 & $75 \cdot 0$ & 25 & 140 & $85 \cdot 0$ & $5 \cdot 6$ \\
\hline & Control & 12 & $83 \cdot 3$ & 23 & 101 & $85 \cdot 1$ & $4 \cdot 4$ \\
\hline
\end{tabular}

increases significantly in a cold environment $\left(P=0 \cdot 05, \chi^{2}\right.$-test of $\mathrm{B} \times \mathrm{B}$ fertility in cold $v$. control). The fertility differential between buffies and the other genotypes seen at higher temperatures is eliminated at the $6^{\circ} \mathrm{C}$ temperature.

The numbers of litters produced by fertile crosses in the cold compared to fertile control crosses do not differ significantly for any genotypes (based on $t$-tests of paired differences, Dixon and Massey, 1969). The higher total number of young born to buffies in the cold room reflects the larger number of fertile crosses there.

Nestling mortality was drastically higher in the cold environment for the offspring of all homozygotes (table 2). In the cold room, mortality

TABLE 2

Nestling mortality in the cold temperature experiments

\begin{tabular}{|c|c|c|c|c|c|c|}
\hline \multirow{3}{*}{$\begin{array}{c}\text { Parental } \\
\text { type } \\
+\times ð\end{array}$} & & \multicolumn{3}{|c|}{ Number of litters in which } & \multirow{2}{*}{\multicolumn{2}{|c|}{$\begin{array}{l}\text { Number } \\
\text { of offspring }\end{array}$}} \\
\hline & & \multirow{2}{*}{$\begin{array}{l}\text { all young } \\
\text { survived }\end{array}$} & \multirow{2}{*}{$\begin{array}{c}\text { some } \\
\text { survived }\end{array}$} & \multirow{2}{*}{$\begin{array}{c}\text { all } \\
\text { died }\end{array}$} & & \\
\hline & & & & & survived & died \\
\hline \multirow[t]{2}{*}{$\mathrm{A} \times \mathrm{A}$} & Cold & 8 & 6 & $6)_{*}$ & 60 & $36)$ \\
\hline & Control & 18 & 3 & $2\}^{*}$ & 92 & $11\}^{3}$ \\
\hline \multirow[t]{2}{*}{$A^{w} \times A^{w}$} & Cold & 8 & 4 & $4)_{*}$ & 48 & $22\}$ \\
\hline & Control & 15 & 2 & $0\}^{*}$ & 68 & $3\}^{\prime}$ \\
\hline \multirow[t]{2}{*}{$\mathrm{B} \times \mathrm{B}$} & Cold & 11 & 4 & $11\}_{*}$ & 68 & 65 \\
\hline & Control & 11 & 0 & $0\}^{*}$ & 60 & $0)^{\circ}$ \\
\hline \multirow[t]{2}{*}{$\mathrm{H} \times \mathbf{H}$} & Cold & 17 & 4 & 4 & 119 & 21 \\
\hline & Control & 17 & 2 & 4 & 86 & 15 \\
\hline
\end{tabular}

often affected whole litters, especially those of buffy parentage. The loss of whole litters accounted for 91 per cent of the offspring lost by buffy parents in the cold room, compared to 64 per cent for agoutis and 62 per cent for heterozygotes. In the control group, 43 per cent of the agouti and 80 per cent of the heterozygote juvenile mortality was due to the loss of whole litters; no buffy young died in the control group. Barnett et al. (1971) also found that the main mortality effects on young captive house mice kept at $-3^{\circ} \mathrm{C}$ were on whole litters. Only the heterozygotes in my study showed no evidence that the viability of their young was adversely affected at the lower temperature. Analysis of the nestling mortality shows 
that the differences in mortality are correlated with the genotype of the parents, not of the young. Heterozygotes bred in cold temperatures produced 29 buffies, of which only one died; their sibs in the control room produced 26 buffies, of which two died. In contrast, almost half the offspring of buffy parents in the cold room died (table 2). Within each of the two environments, there was also a significant difference in the survival of young from parents of different genotypes $(P<0.001$ in the cold room; $\mathrm{P}=0.01$ in the control group; $\chi^{2}$-tests).

An important difference emerged in the growth patterns of offspring of different genotypes in cold and control environments (fig. 1). The offspring of buffy and heterozygous parents showed a similar and steady weight gain in their first 18 days of life in both environments. In contrast, the offspring from homozygous agouti parents kept in the cold began to level off in weight at about 14 days of age, while the control continued to gain steadily. The differences in weight at days 15-18 are significant for the offspring of agoutis $(\mathrm{P}=0.005)$ based on $t$-tests of differences between paired mean weights in the cold and control groups. The weights of litters born to buffies and heterozygotes in the two environments do not differ significantly at these ages. Microtus mothers normally wean their litters at about 14 days of age, so the retarded growth of the agouti offspring may be due to poor feeding behaviour after weaning.

Another feature of the comparative growth rates (fig. 1) is that the offspring of homozygous agoutis and heterozygotes in the cold room weigh less on the average than the control group $(P=0.005$ for each of the three comparisons of paired mean weights, based on $t$-tests). The mean weights of buffy offspring do not differ significantly.

\section{(ii) Experiment on effect of green food in diet}

A green food supplement clearly enhances the fertility of voles (table 3). All genotypes had a higher number of fertile crosses when given a lettuce supplement, although the difference was statistically significant only for the heterozygotes $\left(\mathrm{P}=0.05 ; \chi^{2}\right.$-test $)$. The combined data indicate a significantly higher fertility of voles receiving a green food supplement (18 fertile crosses compared to 11 in the dry group; $\mathrm{P}=0.05 ; \chi^{2}$-test).

Although the pairs receiving lettuce produced a slightly higher number of litters than the corresponding fertile pairs not given lettuce, the differences

TABLE 3

Reproductive data from the green food supplement experiment

$\begin{array}{clcccccc}\begin{array}{c}\text { Parental } \\ \text { type }\end{array} & \begin{array}{c}\text { Fertile* } \\ \text { crosses }\end{array} & \begin{array}{c}\text { No. of } \\ \text { litters }\end{array} & \begin{array}{c}\text { No. } \\ \text { born }\end{array} & \begin{array}{c}\text { No. } \\ \text { weaned }\end{array} & \begin{array}{c}\% \\ \text { weaned }\end{array} & \begin{array}{c}\text { Mean } \\ \text { litter size }\end{array} \\ \mathrm{A} \times \mathrm{A} & \text { Green } & 6 & 17 & 80 & 66 & 82 \cdot 5 & 4 \cdot 7 \\ & \text { Dry } & 4 & 10 & 40 & 35 & 87 \cdot 5 & 4 \cdot 0 \\ \mathrm{~B} \times \mathrm{B} & \text { Green } & 5 & 13 & 49 & 40 & 81 \cdot 6 & 3 \cdot 8 \\ & \text { Dry } & 4 & 9 & 39 & 29 & 74 \cdot 4 & 4 \cdot 3 \\ \mathrm{H} \times \mathrm{H} & \text { Green } & 7 & 13 & 60 & 47 & 78 \cdot 3 & 4 \cdot 6 \\ & \text { Dry } & 3 & 6 & 27 & 21 & 77 \cdot 8 & 4.5 \\ \text { Total } & \text { Green } & 18 & 43 & 189 & 153 & 81 \cdot 0 & 4 \cdot 4 \\ & \text { Dry } & 11 & 25 & 106 & 85 & 80 \cdot 2 & 4 \cdot 2\end{array}$

* Seven crosses were set up for cach genotype. 

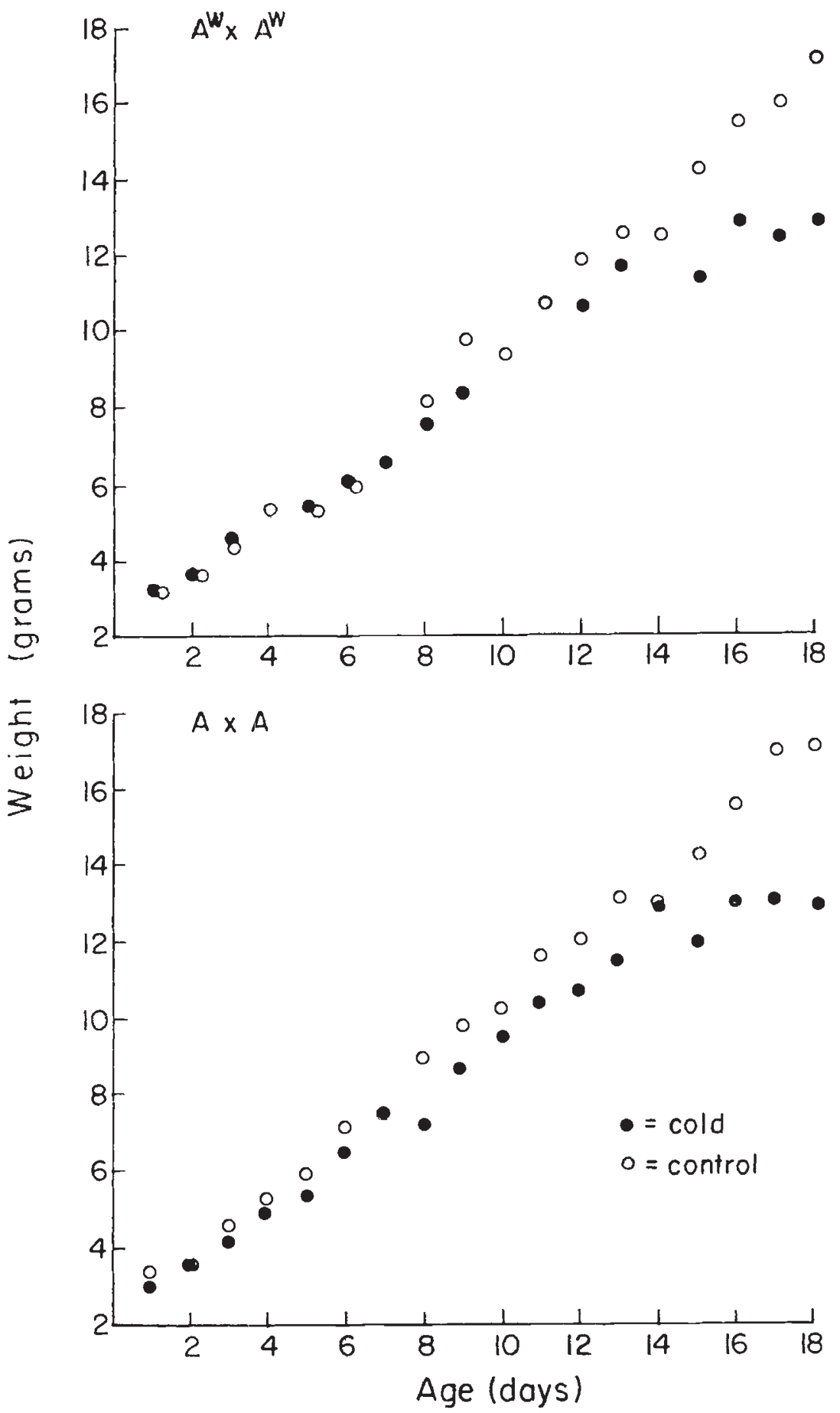

Fig. 1a and 1b.-Age specific weights of offspring born to cold and control groups. 


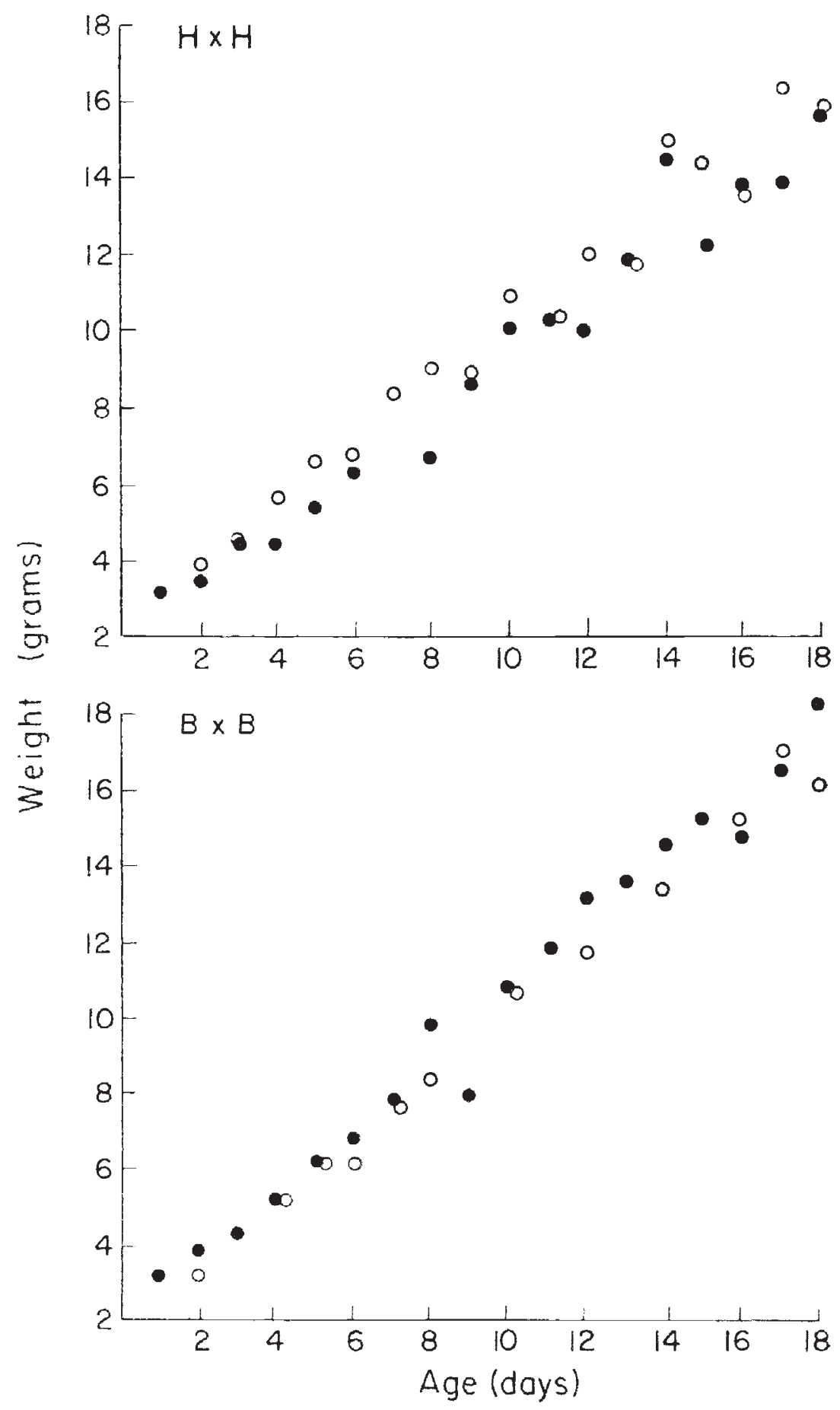

Fir. 1c and 1d.-Age specific weights of offspring born to cold and control groups. 
were not significant ( $t$-test of paired fertile crosses). The larger number of litters born to the green group were basically due to the larger number of fertile crosses. However, there is a difference in the number of offspring born which is independent of the fertility effect. All fertile homozygous agouti parents receiving a lettuce supplement produced a higher total number of offspring than their fertile sibling pairs on a dry diet. This was achieved either by means of larger litters or an extra litter. The difference is significant at the 0.01 level by a $t$-test of paired data. Only the agoutis showed this difference; for buffies and heterozygotes there was no difference in the number of young produced by fertile pairs. Nor was there a significant difference in survival of offspring under the two dietary regimes or between offspring of different genotypes within the green and dry groups.

Only the buffies did not differ significantly in any of the reproductive variables studied, although their reproductive pattern followed the same trend as the other genotypes. The proportion of offspring born to $\mathrm{B} \times \mathrm{B}$ parents under the two dietary regimes differed significantly $(P=0.05$; $\chi^{2}$-test) from that of the other two parental types, the reduction in offspring produced in the dry group being less for buffy parents.

The growth patterns of offspring born to parents of different genotypes varied (fig. 2). The offspring born to buffy parents receiving a lettuce supplement were consistently heavier, on the average, than the offspring of buffies receiving only dry food $(\mathrm{P}=0.005, t$-test $)$. In contrast, there were no significant weight differences in the offspring of homozygous agouti or heterozygous parents. By age 18 days, the offspring of agouti parents weighed relatively less in both environments (an average of $13 \mathrm{~g}$ in the green group and $14 \mathrm{~g}$ in the dry group) than did the offspring of buffies ( $17 \mathrm{~g}$ in green group; $16 \mathrm{~g}$ in dry group) or heterozygotes (18 $\mathrm{g}$ in green group; $16 \mathrm{~g}$ in dry group), as can be seen in fig. 2 . The difference in weight at age 18 days between offspring born to the three different genotypes is significant $(\mathrm{P}=0.05)$, based on the Kruskal-Wallis test (Sokal and Rohlf, 1969).

\section{Discussion}

The fitness of homozygotes in this study was more affected by temperature differences than was that of heterozygotes. The major effects were in improved fertility of buffies at low temperatures, the severe nestling mortality of offspring born to homozygotes, and the slowed growth at $6^{\circ} \mathrm{C}$ of young born to homozygous agoutis. Heterozygotes varied little in reproductive performance or survival and growth of their offspring in the two environments. Hybrids or heterozygotes often show less variation in traits than inbred or homozygous individuals (Falconer, 1960), and this may be due to better buffering of heterozygous individuals (Lerner, 1954). The greater variation in nestling mortality of the homozygotes in the two environments cannot be due simply to better buffering of heterozygous offspring, but it may be that heterozygous parents have an advantage. Half the young born to heterozygotes are homozygotes, and they survived equally as well as their heterozygous siblings and far better than homozygotes born to homozygous parents. The significant differences in nestling mortality must 

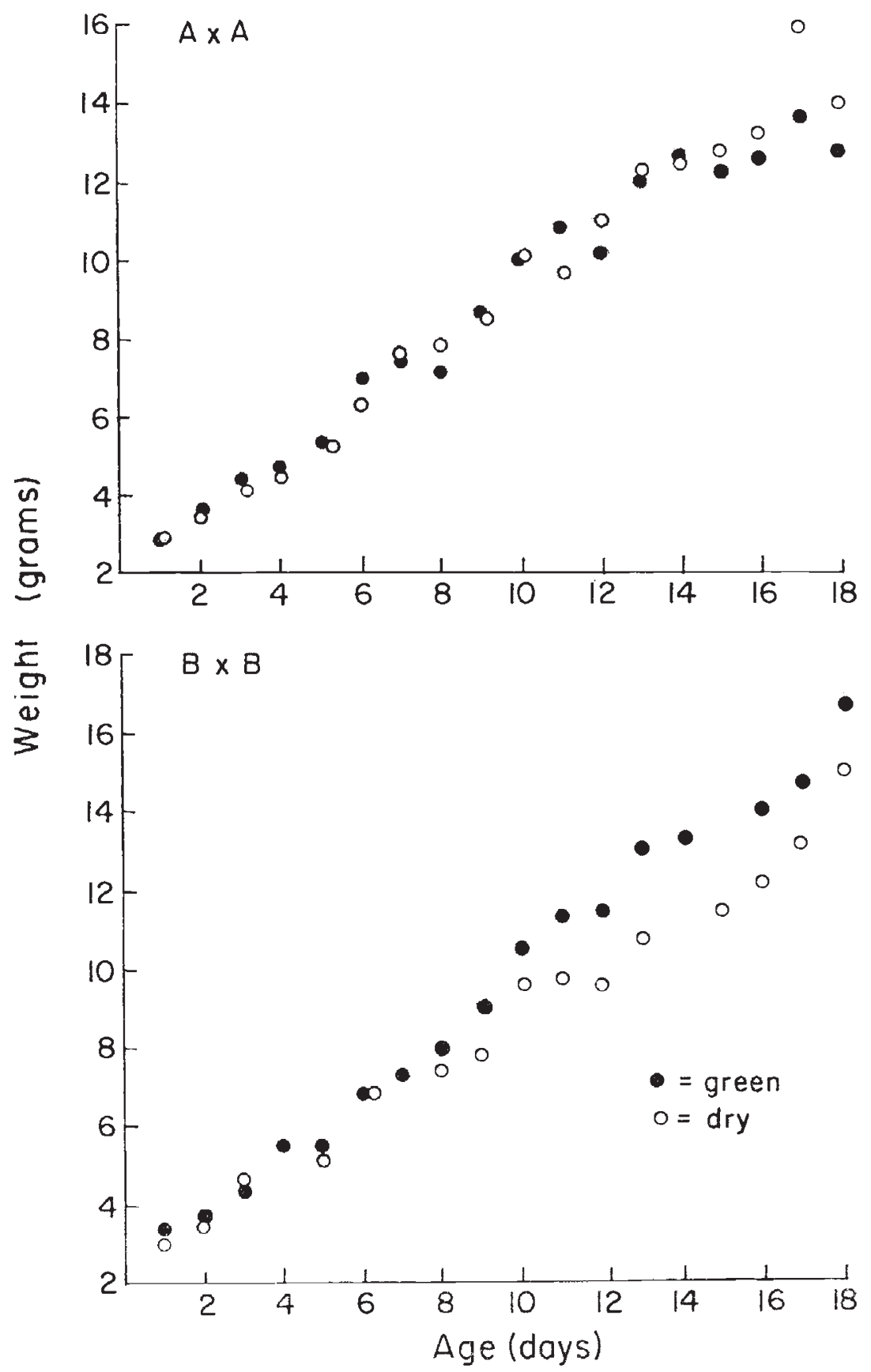

Fro. $2 \mathrm{a}$ and $2 \mathrm{~b}$.-Age specific weights of offspring born to green and dry food groups. 


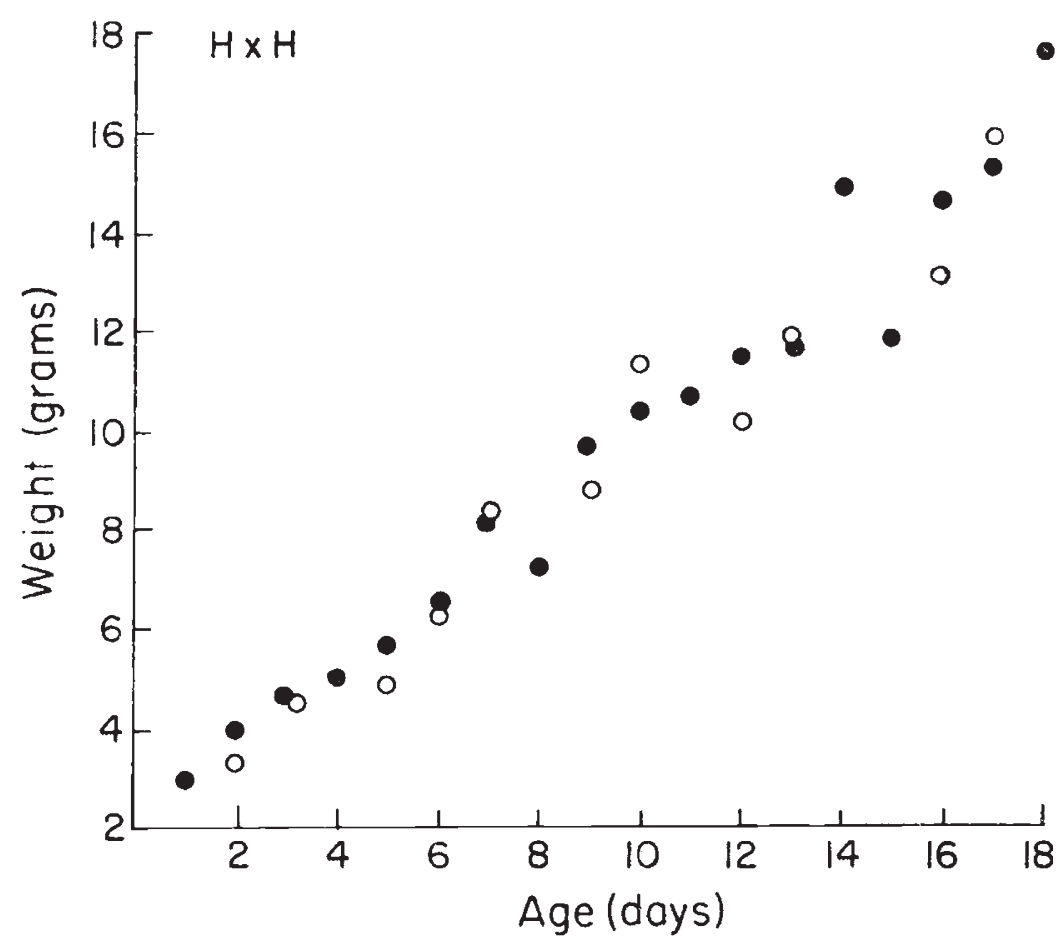

Fig. 2c.-Age specific weight of offspring born to green and dry food groups.

depend on the prenatal environments and postnatal care given by parents of different genotypes, rather than the genotypes of the young themselves.

The great importance of the seasonal rainfall cycle and the associated growth of grasses on the reproduction of Microtus californicus has been reiterated by many researchers (Greenwald, 1957; Hoffmann, 1958; Lidicker and Anderson, 1962). It has been suggested that hormone-like substances in the plants stimulate reproductive activity in the animals eating them (Brody, 1945; Moule et al., 1963; Pinter and Negus, 1965). Berger and Negus (1974), using ovariectomised Microtus montanus, found that substances in lettuce caused uterine hypertrophy, but that these substances were not estrogenic in nature. Negus and Pinter (1966) found that the reproductive performance of Microtus montanus was improved when they were given dietary supplements of either sprouted wheat or extracts of sprouted wheat. In the present experiment on the effect of green food in the diet, I also found a higher reproductive output of voles receiving lettuce, but there were differences in the magnitude of the effect among the genotypes. The differential in fertility was greatest for heterozygous crosses, while differences in the number of offspring produced was greatest for homozygous agouti crosses. Buffies were least sensitive to a lack of green food in the diet.

There are significant seasonal fluctuations in the percentage of buffy individuals in the Brooks Island population (Gill, 1976b). After steadily increasing during the colonisation phase from 1959 to July 1960, the population reached a peak of $1580 /$ ha, then declined and has subsequently 
undergone annual fluctuations. The population density usually peaks in late June and is lowest in December or January. Population growth usually begins around March, about 5 or 6 months after the start of the rainy season and potential primary breeding period (Lidicker, 1973). The percentage of buffies in the population is highest in the July-September quarterly samples, averaging 4.3 per cent, and lowest in the January-March samples, averaging 1.7 per cent. If, at the onset of the dry season with its lack of green vegetation, the reproductive output of the buffy voles does not decrease as rapidly as that of the agoutis on Brooks Island, one would cxpect to find the highest fraction of buffy voles in the July-September samples. Thus, the results of the experiment on green food in the diet are consistent with the field observations.

The results of the cold room experiment do not help explain the autumn peak in buffy frequencies. Extrapolating from these results to the effect of cold weather, one would expect a higher fraction of buffies to be born early in the breeding season, largely due to the contribution from heterozygotes. Most of spring reproduction is the effort of individuals born early that same year. Therefore, assuming they have the same life expectancy as the other genotypes, one would expect the buffies to begin to decline in numbers earlier than the rest of the population, rather than later, as observed. It may be that, if the cold stimulus is operative under field conditions, other sclection pressures are counteracting the expected early increase in buffies.

The deviation from normal growth patterns in the offspring of homozygous agoutis bred in a cold environment is striking (fig. 1). To the extcnt that body size contributes to individual fitness, these differences in growth rate may affect the relative fitnesses of the genotypcs at certain stages. It is noteworthy that in the green food experiment the homozygous agouti offspring tended to be slightly lighter at age 18 days than the offspring of either buffies or heterozygotes (fig. 2). Thus there may be a tendency toward a longer development time for homozygous agoutis at all times of the year.

It is evident from this study that changes in allele frequencics at the buffy locus are not related in a simple way to the important variables of temperature and availability of green plants. Other important selective forces must be operative on Brooks Island, because the agouti phenotypc remains the most abundant. This study has established that significant differences cxist in the reproductive fitnesses of genotypes under two selected environmental parameters, and has demonstrated possiblc sclective forces operating to maintain the buffy allele in the population. Variations in thesc two parameters elicit strong differential genotypic responses in fertility, survival of young, and juvenile growth rates. 'These differences indicate the directions in which the genotypic fitnesses might change with cnvironmental fluctuations. Under most of the conditions tested, the heterozygotes seemed to enjoy an advantage in both reproduction and individual growth.

Acknowledgments. - This is part of a dissertation submitted to the Department of Genetics at the University of California, Berkeley, in partial satisfaction of the requirements for the Doctor of Philosophy degree. While doing this research, I was the recipient of a National Institute of Health Training Grant, awarded by the Department of Genetics at the University of California, Berkeley. Revisions of the work were completed while I was the recipient of a Ford Foundation Post-Doctoral Fcllowship in the Department of Biology at the University of Chicago. 


\section{REFERENCES}

BARNETT, s. A., SMART, J. L., AND STODDART, R. C. 1971. Total reproductive performance of captive house mice at two temperatures. F. Zool. Lond., 163, 443-450.

BERGER, P. J., AND NEGUS, N. C. 1974. Influence of dietary supplements of fresh lettuce on ovariectomized Microtus montanus. 7. Mammal., 55, 747-750.

BRODY, s. 1945. Bioenergetics and Growth, 1023 pp. Reinhold Publ. Corp., N.Y.

DIXON, w. J., AND MAssey, F. J., JR. 1969. Introduction to Statistical Analysis, 3rd Ed, 638 pp. McGraw-Hill, N.Y.

FAlCONER, D. s. 1960. Quantitative Genetics, 365 pp. Ronald Press, N.Y.

GILL, A. E. 1972. Maintenance of a coat-color polymorphism in an island population of the California vole. Ph.D. Thesis, 171 pp., Univ. California, Berkeley, Berkeley, Calif.

Grll, A. E. 1976a. White spotting in the California vole. Heredity, 37, 113-128.

GILL, A. E. 1976b. Maintenance of polymorphism in an island population of the California vole, Microtus californicus. Evolution, in press.

GREENWALD, G. S. 1957. Reproduction in a coastal California population of the field mouse, Microtus californicus. Univ. Calif. Publ. Zool., 54, 421-446.

HOFFMANN, R. s. 1958. The role of reproduction and mortality in population fluctuations of voles (Microtus). Ecol. Monog., 28, 79-109.

LERner, I. M. 1954. Genetic Homeostasis, 134 pp. Oliver \& Boyd, Edinburgh.

LIDICKER, w. z., JR. 1963. The genetics of a naturally occurring coat-color mutation in the California vole. Evol., 17, 340-346.

Lidicker, w. z., JR. 1966. Ecological observations on a feral house mouse population declining to extinction. Ecol. Monog., 36, 27-50.

LIDICKER, w. z., JR. 1973. Regulation of numbers in an island population of the California vole, a problem in community dynamics. Ecol. Monog., 43, 271-302.

LIDICKER, w. z., JR., AND ANDERSON, P. K. 1962. Colonization of an island by Microtus californicus, analysed on the basis of runway transects. F. An. Ecol., 31, 503-517.

MOUle, G. R., BRADEN, A. W. H., AND LAMOND, D. R. 1963. The significance of estrogens in pasture plants in relation to animal production. Anim. Breed. Abst., 31, 139-157.

NEGUS, N. C., AND Pinter, A. J. 1966. Reproductive responses of Microtus montanus to plant extracts in the diet. J. Mammal., 47, 596-601.

PINTER, A. J., AND NEGUS, N. c. 1965. Effects of nutrition and photoperiod on reproductive physiology of Microtus montanus. Amer. 7. Physiol., 208, 633-638.

SOKAL, R. R., AND ROHLF, F. K. 1969. Biometry, 776 pp. W. H. Freeman, S.F. 